\title{
Periodontal Disease in Two Siblings with VPS45-associated Severe Congenital Neutropenia Type V: A Case Report
}

\author{
Faris A Alotaibi ${ }^{1}$, Abdullah I Albarkheel ${ }^{2}$
}

\begin{abstract}
VPS45-associated severe congenital neutropenia type V (VPS45-associated SCN5) is an autosomal recessive disorder caused by defective endosomal intracellular protein trafficking due to mutations in VPS45 underlies a reduced absolute neutrophil count $>500$ cells $/ \mathrm{mm}^{3}$ and impaired neutrophil function. VPS45-associated SCN5 is a very rare condition with only 19 patients previously reported in the literature. Patients suffering from this disorder having profound neutropenia in the first months of life, fever, pneumonitis, skin infections, oral ulcerations, and gingivitis. This paper reports the first two cases of VPS45-associated SCN5 in Saudi Arabia and describes the treatment approaches for periodontal disease as a manifestation of that disorder since the existing dental literature is lacking sufficient information on the management of those kinds of patients. The present two cases reflect the importance of early diagnosis of periodontal disease as a possible indicator of underlying systemic disease. Keywords: Periodontal disease, Severe congenital neutropenia, VPS45. International Journal of Clinical Pediatric Dentistry (2020): 10.5005/jp-journals-10005-1841
\end{abstract}

\section{INTRODUCTION}

VPS45-associated severe congenital neutropenia type V (VPS45associated SCN5) is an autosomal recessive disorder caused by defective endosomal intracellular protein trafficking due to mutations in the VPS45 gene, which is located at chromosome 1q21q22, underlies an impaired neutrophil function. ${ }^{1}$ The mutations in the VPS45 gene have been identified in humans in 2013., Mutations of this gene have been mapped on c.671 C>A; p.T224A, c.712 G>A; p.E238K and c.1403 C>T; p.P468L. ${ }^{1-4}$ VPS45-associated SCN5 is characterized by severely reduced levels of neutrophils in the blood by peripheral blood absolute neutrophil count (ANC) $<500$ cells $/ \mathrm{mm}^{3}$. $^{5}$

The common clinical features include profound neutropenia in the first months of life, failure to thrive, fever, pneumonitis, skin infections, bone marrow failure, hepatosplenomegaly, and nephromegaly. ${ }^{1-6}$ The prevalence of severe congenital neutropenia (SCN) is 0.7 per million inhabitants, ${ }^{7}$ however, VPS45associated SCN5 is a very rare condition with only 19 patients previously reported in the literature. ${ }^{1-4,8}$ The most reported oral manifestations of SCN include painful aphthous ulcers, gingival inflammation with edematous and fiery-red gingiva, gingival recession, alveolar bone loss, tooth mobility, and premature tooth loss of both dentitions..$^{9-15}$

Many pharmacological agents are recommended in the treatment of SCN patients, such as, corticosteroids, androgens, prophylactic antibiotics, splenectomy, or cytotoxic therapy. ${ }^{16,17}$ Recently, hematopoietic growth factors produced by genetic engineering, recombinant human granulocyte-colony-stimulating factor (G-CSF), are considered to be an effective therapy for increasing the circulating neutrophils count. ${ }^{13,18,19}$ However, the curative option for patients with VPS45-associated SCN5 is hematopoietic stem cell transplant., ${ }^{7,8}$

The existing dental literature is lacking sufficient information on the dental management of those kinds of patients. The purpose of this paper is to report the first two cases of VPS45-associated SCN5 in Saudi Arabia caused by homozygous mutation in the VPS45 gene (c.1229 T>C p.Leu410Pro) on chromosome 1q as well
${ }^{1}$ Department of Pediatric Dentistry, King Saud Medical City, Riyadh, Kingdom of Saudi Arabia

${ }^{2}$ Department of Pediatric Dentistry, King Abdulaziz Medical City, Riyadh, Kingdom of Saudi Arabia

Corresponding Author: Faris A Alotaibi, Department of Pediatric Dentistry, King Saud Medical City, Riyadh, Kingdom of Saudi Arabia, Phone: +966568884668, e-mail: faalotaibi@ksmc.med.sa

How to cite this article: Alotaibi FA, Albarkheel Al. Periodontal Disease in Two Siblings with VPS45-associated Severe Congenital Neutropenia Type V: A Case Report. Int J Clin Pediatr Dent 2020;13(5):572-575.

Source of support: Nil

Conflict of interest: None

as to describe the treatment approaches for periodontal disease as a manifestation of VPS45-associated SCN5.

\section{Case Description}

Two Saudi female siblings (a 3-year and 9-month-old girl and a 22-month-old girl) with a known case of autosomal recessive SCN type V, caused by homozygous mutation in the VPS45 gene (c.1229 T>C p.Leu410Pro) on chromosome 1q, were referred to the Department of Pediatric Dentistry in King Abdulaziz Medical City in Riyadh, Saudi Arabia. The pediatric hematologist referred to the two sisters for evaluating the chronic inflammation of the gingiva.

The medical history of the older sister revealed that her ANC was $<200$ cells $/ \mathrm{mm}^{3}$ at the time of the diagnosis, a G-CSF was administered subcutaneously twice weekly. In addition, she is suffering from frequent upper respiratory tract infections and she is the child of carrier parents. Whole-exome sequencing confirmed a homozygous mutation in the VPS45 gene (c.1229 T>C p.Leu410Pro) on chromosome 1q, leading to the diagnosis of VPS45-associated SCN5. Upon clinical examination, all the primary teeth were present except the maxillary left central incisor which is prematurely lost due to severe bone loss. She had multiple carious lesions, severe edematous and inflamed gingiva, deep periodontal pockets 
with clinical attachment level measurements ranged from 4 to 7 $\mathrm{mm}$, and bleeding on probing, many degrees of teeth mobility, and heavy plaque accumulation with poor oral hygiene (Fig. 1). Periapical radiographs showed an alveolar bone loss affecting all the existing teeth, but the mandibular incisors were affected more severely (Fig. 2).

The medical history of the younger sister revealed that her ANC was $<200$ cells $/ \mathrm{mm}^{3}$ at the time of the diagnosis, a G-CSF was administered subcutaneously twice weekly. In addition, she is suffering from frequent upper respiratory tract infections similar to her older sister. Upon clinical examination, all the primary teeth were present except the primary second molars. She had mild edematous and inflamed gingiva with bleeding on probing (Fig. 3). Periapical radiographs were not taken due to child cooperation.

The health condition of the older sister as well as the level of cooperation necessitates to treat her under general anesthesia. The hematologist would like to admit her to the hospital 3 days before the procedure for monitoring of neutrophil count. The hematologist planned to start on $5 \mathrm{mg} / \mathrm{kg}$ G-CSF 3 days before and 3 days after the procedure. In addition, a single dose of cefepime $825 \mathrm{mg}$ was given before the procedure as antibiotic prophylaxis and followed by antibiotic coverage. The treatment plan was established to remove any pulpally involved teeth to reduce the future risk of chronic bacteremia and to remove any mobile teeth due to alveolar bone loss (Fig. 4).

The plan for the younger patient consisted of a plaque control program, fluoride application, dietary analysis and advice, recall

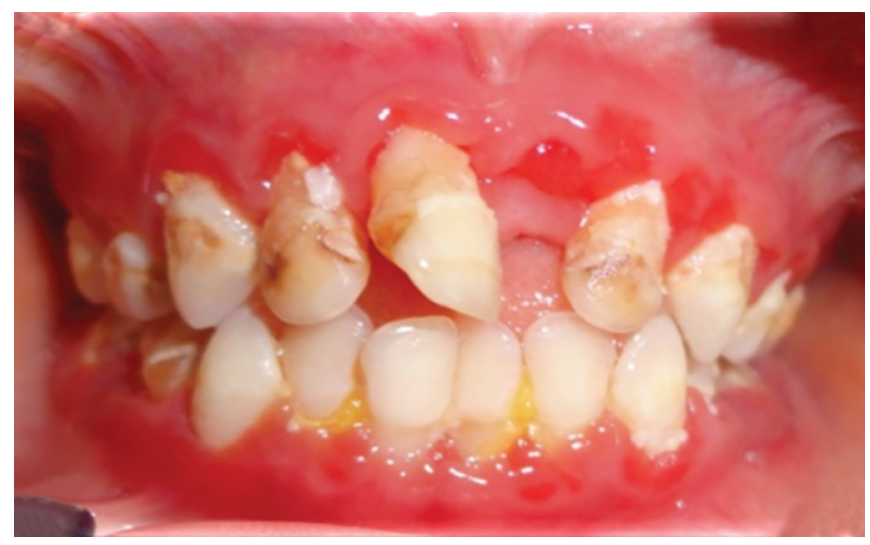

Fig. 1: Preoperative intraoral photograph for the older sister (frontal view) visits for examination and reinforcement as well as parental education.

\section{Discussion}

Neutrophils play a significant role in inflammation as well as wound healing, and function as the first line of defense against pathogenic microorganisms. Defects in the production and life cycle of neutrophils are the cause of the development of gingivitis which progresses to aggressive periodontitis in primary and permanent dentitions leading to a premature loss of teeth with adverse psychological effects. ${ }^{20-22}$ Severe generalized gingivitis, tooth mobility, alveolar bone loss, and premature tooth loss in both dentitions are also common features in $\mathrm{SCN} .{ }^{23,24}$ These features are consistent with the present cases.

The prognosis of patients with SCN has been improved with G-CSF therapy. Despite adequate oral hygiene, some patients with SCN still suffering from frequent periodontal inflammation. ${ }^{22}$ Although both sisters are on G-CSF, they still suffer from periodontal disease. Thus, adjusting the ANC to the normal levels is insufficient to maintain good oral health in SCN patients because of the defect of the antibacterial peptide LL-37. ${ }^{25,26}$ The side effects of SCN can be minimized with appropriate preventive measures and treatment approaches. The most effective way includes antimicrobials and frequent maintenance appointments. ${ }^{23,27}$ Several studies recommend swabbing with $0.2 \%$ chlorhexidine gluconate twice daily by the parent to decrease dental plaque accumulation and dental caries. ${ }^{19,28-32}$

Surgical intervention could be the only option in treating patients with severe periodontitis as a manifestation of systemic diseases, such as, VPS45-associated SCN5. To reduce the risk of bacteremia, extraction of pulpally involved teeth and using

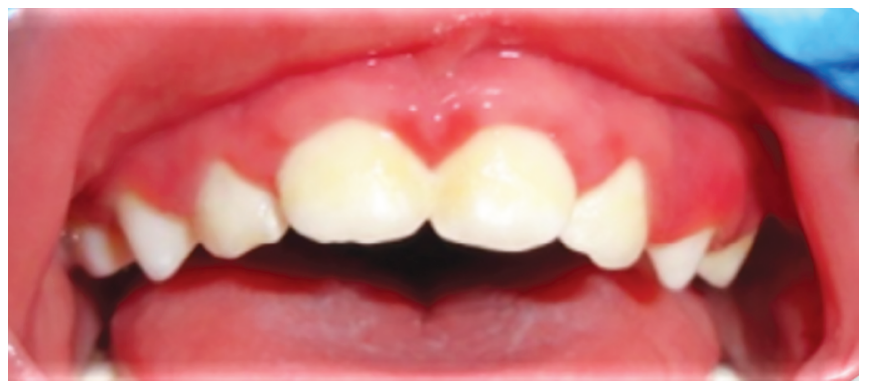

Fig. 3: Preoperative intraoral photograph for the younger sister (frontal view)
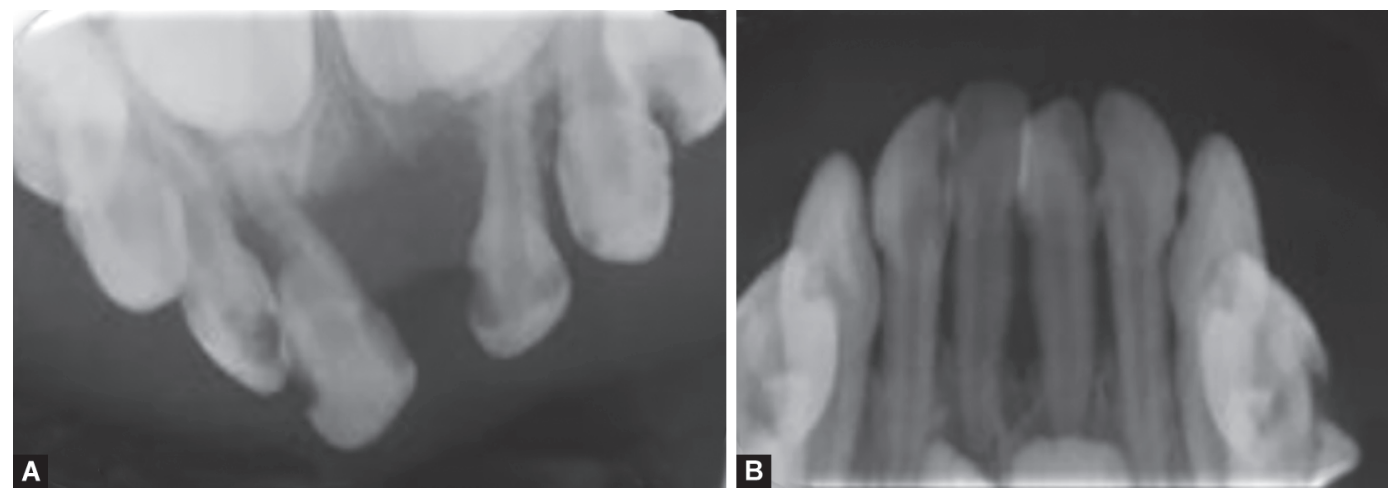

Figs $2 \mathrm{~A}$ and B: Preoperative radiograph for the older sister (upper and lower periapical views) 

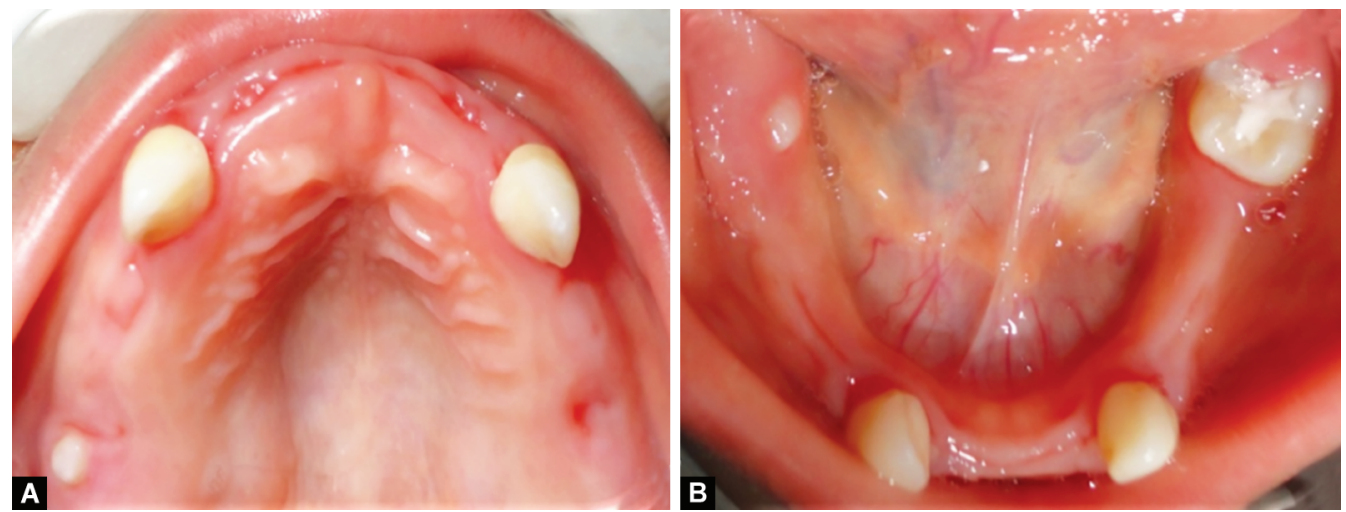

Figs 4A and B: Postoperative intraoral photographs for the older sister (upper and lower occlusal views)

antibiotics coverage before and after any dental procedure with soft tissue manipulation is recommended for such cases. ${ }^{33}$

\section{Conclusion}

The present two cases reflect the importance of early diagnosis of periodontal disease as a possible indicator of underlying systemic disease. There is an urgent need for a call to focus on oral health for patients with hematological diseases, such as, congenital neutropenia as well as promoting awareness of the interdisciplinary relationship between different specialties. Genetic counseling and parental education are substantial in the prevention protocols.

\section{References}

1. Vilboux T, Lev A, Malicdan MC, et al. A congenital neutrophil defect syndrome associated with mutations in VPS45. N Engl J Med 2013;369(1):54-65. DOI: 10.1056/NEJMoa1301296.

2. Stepensky P, Saada A, Cowan M, et al. The Thr224Asn mutation in the VPS45 gene is associated with the congenital neutropenia and primary myelofibrosis of infancy. Blood 2013;121(25):5078-5087. DOI: 10.1182/blood-2012-12-475566.

3. Meerschaut I, Bordon V, Dhooge C, et al. Severe congenital neutropenia with neurological impairment due to a homozygous VPS45 p.E238K mutation: a case report suggesting a genotypephenotype correlation. Am J Med Genet A 2015;167A(12):3214-3218. DOI: 10.1002/ajmg.a.37367.

4. Shah R, Munson M, Wierenga K, et al. A novel homozygous VPS45 p.p468I mutation leading to severe congenital neutropenia with myelofibrosis. Pediatr Blood Cancer 2017;64(9):e26571. DOI: 10.1002/ pbc. 26571.

5. Zeidler C, Germeshausen $M$, Klein C, et al. Clinical implications of ELA2-, HAX1-, and G-CSF-receptor (CSF3R) mutations in severe congenital neutropenia. Br J Haematol 2009;144(4):459-467. DOI: 10.1111/j.1365-2141.2008.07425.x.

6. Kostmann R. Infantile genetic agranulocytosis (agranulocytosis infantilis hereditaria): a new recessive lethal disease in man. Acta Paediatr Scand 1956;45(3):1-78. DOI: 10.1111/j.1651-2227.1956. tb06875.x.

7. Donadieu J, Fenneteau O, Beaupain B, et al. Congenital neutropenia: diagnosis, molecular bases and patient management. Orphanet J Rare Dis 2011;6:26. DOI: 10.1186/1750-1172-6-26.

8. Shadur B, Asherie N, Newburger PE, et al. How we approach: severe congenital neutropenia and myelofibrosis due to mutations in VPS45. Pediatr Blood Cancer 2019;66(1):e27473. DOI: 10.1002/pbc.27473.

9. Andrews RG, Benjamin S, Shore N, et al. Chronic benign neutropenia of childhood with associated oral manifestations. Oral Surg Oral Med Oral Pathol 1965;20(6):719-725. DOI: 10.1016/0030-4220(65)90133-7.
10. Mishkin DJ, Akers JO, Darby JP. Congenital neutropenia. report of a case and a biorationale for dental management. Oral Surg Oral Med Oral Pathol 1976;42(6):738-745. DOI: 10.1016/0030-4220(76)90096-7.

11. Symons AL. Persistent neutropenia in a young child with a chromosome anomaly. case report. Aust Dent J 1987;32(2):91-94. DOI: 10.1111/j.1834-7819.1987.tb05371.x.

12. Lamster IB, Oshrain RL, Harper DS. Infantile agranulocytosis with survival into adolescence: periodontal manifestations and laboratory findings. J Periodontol 1987;58(1):34-39. DOI: 10.1902/ jop.1987.58.1.34.

13. Kirstila V, Sewon L, Laine J. Periodontal disease in three siblings with familial neutropenia. J Periodontol 1993;64(6):566-570. DOI: 10.1902/ jop.1993.64.6.566.

14. Yamalık N, Yavuzyılmaz E, Çaglayan F, et al. Periodical gingival bleeding as a presenting symptom of periodontitis due to underlying cyclic neutropenia. Aust Dent J 1993;38(4):272-276. DOI: 10.1111/ j.1834-7819.1993.tb05495.x.

15. Genco RJ, Wilson ME, Nardin ED. Periodontal complications and neutrophil abnormalities Genco RJ, Goldman HM, Cohen DW, ed. Contemporary periodontics. Philadelphia: Mosby; 1990. p. 16.

16. Dale DC, Guerry D, Wewerka J, et al. Chronic neutropenia. Medicine 1979;58(2):128-144. DOI: 10.1097/00005792-197903000-00002.

17. Dale DC, Bolyard AA. An update on the diagnosis and treatment of chronic idiopathic neutropenia. Curr Opin Hematol 2017;24(1):46-53. DOI: $10.1097 / \mathrm{MOH} .0000000000000305$.

18. Jakubowski AA, Souza L, Kelly F, et al. Effects of human granulocyte colony-stimulating factor in a patient with idiopathic neutropenia. $\mathrm{N}$ Engl J Med 1989;320(1):38-42. DOI: 10.1056/NEJM198901053200107.

19. Sorin MS. Cyclic neutropenia: dental observations, treatment with granulocyte colony-stimulating factor. J Clin Pediatr Dent 1993;17:183-188.

20. Garant PR. Plaque-neutrophil interaction in monoinfected rats as visualized by transmission electron microscopy. J Periodontol 1976;47(3):132-138. DOI: 10.1902/jop.1976.47.3.132.

21. Hajishengallis $E$, Hajishengallis G. Neutrophil homeostasis and periodontal health in children and adults. J Dent Res 2014;93(3):231237. DOI: $10.1177 / 0022034513507956$.

22. Attstrom R, Schroeder HE. Effect of experimental neutropenia on initial gingivitis in dogs. Scand J Dent Res 1979;87(1):7. DOI: 10.1111/ j.1600-0722.1979.tb01935.x.

23. Defraia E, Marinelli A. Oral manifestations of congenital neutropenia or Kostmann syndrome. J Clin Pediatr Dent 2001;26(1):99-102. DOI: 10.17796/jcpd.26.1.n1vhq267271378I1.

24. Prichard JF, Ferguson DM, Windmiller J, et al. Prepubertal periodontitis affecting the deciduous and permanent dentition in a patient with cyclic neutropenia. J Periodontol 1984;55(2):114-122. DOI: 10.1902/ jop.1984.55.2.114.

25. Carlsson G, Wahlin YB, Johansson A, et al. Periodontal disease in patients from the original Kostmann family with severe congenital 
neutropenia. J Periodontol 2006;77(4):744-751. DOI: 10.1902/ jop.2006.050191.

26. Carlsson G, Aprikyan AA, Ericson KG, et al. Neutrophil elastase and granulocyte colony-stimulating factor receptor mutation analyses and leukemia evolution in severe congenital neutropenia patients belonging to the original Kostmann family in northern Sweden. Haematologica 2006;91(5):589-595.

27. Chauhan VS, Chauhan RS, Devkar N, et al. Gingival and periodontal diseases in children and adolescents. J Dent Allied Sciences 2012;1(1):26-29. DOI: 10.4103/2277-4696.159114.

28. Larizza L, Roversi G, Volpi L. Rothmund-Thomson syndrome. Orphanet J Rare Dis 2010;5:2. DOI: 10.1186/1750-1172-5-2.

29. Ho W, Cheretakis C, Durie P, et al. Prevalence of oral diseases in Shwachman-diamond syndrome. Spec Care Dentist 2007;27(2):52-58. DOI: 10.1111/j.1754-4505.2007.tb00328.x.
30. Buduneli N, Cogulu D, Kardesler L, et al. Dental findings and treatment in consanguinity associated congenital chronic familial neutropenia. J Clin Pediatr Dent 2006;31(2):123-126. DOI: 10.17796/jcpd.31.2.x782 $45364736262 \mathrm{k}$

31. Yildirim S, Yapar M, Kubar A. Detection and quantification of herpesviruses in Kostmann syndrome periodontitis using real-time polymerase chain reaction: a case report. Oral Microbiol Immunol 2006;21(2):73-78. DOI: 10.1111/j.1399-302X.2006.00250.x.

32. Hakki SS, Aprikyan AA, Yildirim S, et al. Periodontal status in two siblings with severe congenital neutropenia: diagnosis and mutational analysis of the cases. J Periodontol 2005;76(5):837-844. DOI: 10.1902/jop.2005.76.5.837.

33. Bos MM, Smeets LS, Dumay l, et al. Bloodstream infections in patients with or without cancer in a large community hospital. Infection 2013;41(5):949-958. DOI: 10.1007/s15010-013-0468-1. 